\title{
Practical approach to handle large classes: A case study for keeping sessions Live
}

\author{
Sachin S. Patil \\ Dept. of CSE, \\ Rajarambapu Institute of Technology,Islampur. \\ Dist: Sangli-415 414 Maharashtra. \\ e-mail: sachin.patil@ritindia.edu
}

\author{
Shivananda R. Poojara \\ Dept. of CSE, \\ Rajarambapu Institute of Technology, Islampur \\ Dist: Sangli-415 414-Maharashtra \\ e-mail: shivananda.poojara@ritindia.edu
}

\author{
Khyamling A Parane \\ Dept. of CSE, \\ Rajarambapu Institute of Technology, Islampur. \\ Dist: Sangli-415 414 Maharashtra. \\ e-mail: khyamling.parane@ritindia.edu
}

\begin{abstract}
Today's graduate is characterize to be self directed, process-oriented, product-oriented, casuistic and possess lifelong learning skills. They also need to be critical thinker, creative, problem solvers, innovator and analytical in their approach. In present teaching scenario of Engineering, some faculties are still practicing the traditional approach of delivery the lecture in large classroom such as chalkand-talk or pen-and-paper teaching. Teaching the course of Theory of Computations (TOC) at B Tech and Software architecture at $M$ Tech level is challenging because of their more mathematical and theoretical nature respectively. In addition, the conventional approach to course teaching for noninteractive mathematical solutions \& heavy architectural of software design, make the classrooms more steady.
\end{abstract}

We identified problem of in-activeness of students in large classroom learning theoretical subjects. Solution for the problem is identified using best practice method [1]. Root causes were identified in analysis phase of best practice method for large

\footnotetext{
Sachin S. Patil

Dept. of CSE

Rajarambapu Institute of Technology, Islampur.

Dist: Sangli-415 414 Maharashtra.

e-mail:sachin.patil@ritindia.edu
}

classroom dynamics and to make joyful learning. This was taken as basis for development of a solution and we identified the best solution as think and ink, Activity based learning [2], Group Discussion [5], JFLAP simulation tool [4], Crossword[11], Alice tool[10], proprietary software package presentations as group assignment to deal realistic scenario.

Keywords - TOC, Software Architecture, JFLAP, Think and Ink, Classroom Dynamics, Crossword, Alice;

\section{Introduction}

The objective of the engineering education is to prepare students to solve the practical problems, employability and as a lifelong learning. This could be done by making joyful learning in the large classroom dynamics. Students learn in many ways - by seeing and hearing; reflecting and acting; reasoning logically and intuitively; memorizing and visualizing and drawing analogies and building mathematical models; steadily and in fits and starts. Teaching methods also vary. Some instructors deliver the lectures, others demonstrate or discuss; some focus on principles and others on applications; some emphasize memory and others understanding. How much a student learns in a class is governed in part by that student's native ability and prior preparation but also by the compatibility of his or her learning style and the instructor's teaching style. 
In traditional approach of teaching style, students assume to be purely passive role and their concentration fades off after 15-20 minutes. More emphasis has been given on theory without any practical and real life time situations, learning from memorization but not by understanding, so students can no longer survive by memorizing textbooks. They now need to explore and experience genuine tasks that connects to the real-world; in which they can develop, master, and demonstrate authentic skills. Engineering Education needs to move from a theoretical to practical approach of teaching. The practical approaches of teaching play an important role to understand, involve and learn the course effectively.

Teaching the course of Theory of Computations (TOC) at B Tech and Software architecture at M Tech level is challenging because of their more mathematical and theoretical nature respectively.

We made an attempt to overcome the problems, so as to transform the idle environment of students in the large classroom to active participation by demonstrating the concepts using activity play, role play, group discussion, think and ink etc. Further section I, deals with the detail problem statement, section II discusses literature survey III discusses the implementation, IV discusses the Result and observations, finally section discuss the outcomes.

\section{Problem Statement}

Getting student's attention in class has been a challenge for educators in technology. Mismatches exist between common learning styles of engineering students and traditional teaching styles of engineering professionals. In consequence, students become bored and inattentive in class, do poorly on tests and get discouraged about the courses, curriculum, and themselves. Most seriously, society loses potentially excellent engineers [1].

In the field of computer science, subjects are more imaginary and conceptual rather than practical. Some of identified subjects which come under this category are:

1. Computer organization

2. Discrete Mathematics

3. Micro processer

4. Theory of computation

5. Software Architecture

\section{Computer Graphics.}

The identified problem lies in all subjects mentioned above and also for various subjects in the engineering curriculum. As per discussion experts in field and review from students, the courses under experimentation viz. Theory of Computation and Software Architecture are important in curriculum, as

Table- 1: Rating for each difficult subject.

\begin{tabular}{|c|l|c|c|c|c|c|c|c|c|}
\hline \multirow{2}{*}{ Sr.No. } & \multirow{2}{*}{ PROBLEM } & SSP & SRP & KAP & ASM & SDY & PBR & Total \\
\cline { 3 - 7 } & & \multicolumn{6}{|c|}{ (Max. rating: 5 each) } \\
\hline 1 & $\begin{array}{l}\text { Computer } \\
\text { organization }\end{array}$ & 2 & 3 & 2 & 3 & 3 & 3 & 16 \\
\hline 2 & $\begin{array}{l}\text { Discrete } \\
\text { Matematics }\end{array}$ & 3 & 2 & 2 & 5 & 2 & 2 & 16 \\
\hline 3 & $\begin{array}{l}\text { Micro } \\
\text { processer }\end{array}$ & 5 & 3 & 3 & 3 & 4 & 2 & 20 \\
\hline 4 & $\begin{array}{l}\text { Theory of } \\
\text { Computation }\end{array}$ & 5 & 4 & 4 & 4 & 5 & 4 & 26 \\
\hline 5 & $\begin{array}{l}\text { Software } \\
\text { Architecture }\end{array}$ & 5 & 4 & 4 & 4 & 5 & 4 & 26 \\
\hline 6 & $\begin{array}{l}\text { Computer } \\
\text { Graphics. }\end{array}$ & 4 & 3 & 3 & 3 & 3 & 2 & 18 \\
\hline
\end{tabular}

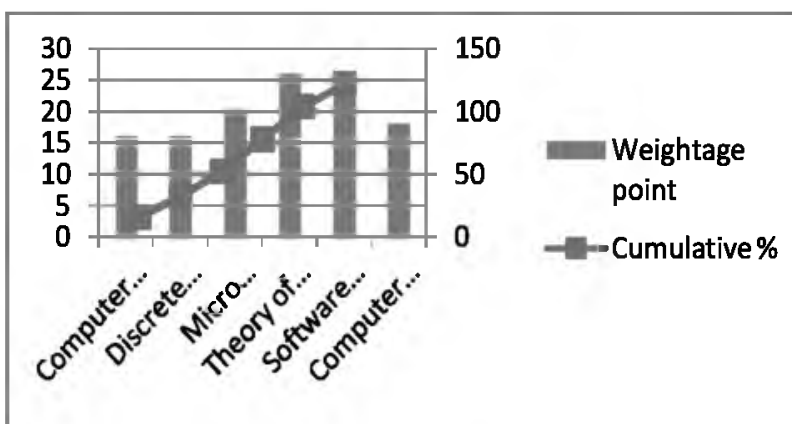

Figure 1: Pareto diagram showing rating in Table- 1. this course is a prerequisite for further related courses as system software and compiler design, software engineering respectively and also the concepts learnt in this course are widely applicable in the computer science and related engineering fields.

As above mentioned and a part of Best Practice method, rating method used as a tool to identify subjects which are toughest, theoretical, monotonical and mathematical in nature. This were taken as basis for development of a solution and with a thought process was seen for best solution as Think and Ink, Activity based learning [2], Group Discussion[5], JFLAP simulation tool[4], crossword[11], Alice tool[10].

\section{Literature Survey}

It is been surveyed that, the students in large classroom are inattentive after 20-30 minutes because of traditional teaching style. Recent year's surveys 
have exhaustively enumerated deficiencies in engineering education. The major factors that affect learning are teaching innovation \& understanding the classroom dynamics. There are many factors that affect the students' learning satisfaction and learning effectiveness. Other than a student's personal factors, factors such as teachers \& mode of conduction, courses and learning environment, participation, assessment etc. all may have an impact on students learning. Teaching innovation means the introduction of new teaching ideas, methods or tools, while creative teaching is the development and the use of novel, original, or inventive teaching methods. The Innovative way of teaching makes students active participation in the classroom.

The literature survey lead to innovative methods of teaching learning adopted in engineering education. Some of the case studies and key observations mentioned below illustrate the importance of Innovative methods of teaching learning.

\section{A. Activity based learning:}

"Activity Based Teaching Learning in Formal Languages and Automata Theory - An Experience" [2] method was adopted at II year B Tech students. The authors observed that, this technique has resulted in increased participation and learning of students as evident in their performance. Students expressed that, the pressure during examinations is reduced as they were comfortable with their learning through activities \& have more clearance toward difficult concept.

"A study on learning ability in elementary school mathematics based on ABL (Activity Based Learning) approach" [3] presents an investigation on the ABL (Activity Based Learning) \& also the learning abilities of students in mathematics were tested. The sample consisted of 1042 students from IX and $\mathrm{X}$ standard. A survey method was adopted. The results clearly indicate that the $\mathrm{ABL}$ (Activity Based Learning) method is suited to the students in understanding mathematical concepts in better way.

\section{B. JFLAPSimulation tool:}

"Increasing Engagement in Automata Theory with JFLAP" [4] was adopted II year B Tech students, the authors observed that results of study show that, majority of students experienced a easy look through to concepts with JFLAP which in return was more engaging and more enjoyable. Over half of the students got better grades as compared to their expectations \& earlier results.

\section{Group Discussion:}

"Using video clips, small group discussions and student surveys to teach a general education module (gem)" [5] was adopted II year B. Tech mechanical engineering, subject was "Fluid Mechanics I" approximately 350 students were enrolled. As per surveyed the results clearly indicate that the Group discussion method was useful for reinforcing difficult concepts and allow students to articulate their ideas, build up their self-confidence. Students were question and challenge their classmates' answers and viewpoints, as well as to facilitate critical thinking. After the discussion, the mentor would give the groups an opportunity to present their answers and to explain the reasoning behind them.

\section{Implementation}

Development Of Solution :

Root causes were identified in analysis phase of best practice method for large classroom dynamics and to make joyful learning. This was taken as basis for development of a solution and we identified the best solution as -

"Making joyful teaching learning of TOC and Software Architecture subjects in the class room and tutorials"

To implement the solution, has found group of use cases which makes students an active and lifelong learners.

\section{Use cases:}

A. Think and Ink use case:

Think and Ink is one of the novel technique helps to make understand concepts and assess students quickly. Basically this activity is conducted in tutorials as well as classroom. Once completion of theoretical concepts in large classroom and sequentially Think and Ink use case can be played in tutorials.

Process to conduct activity:

Step 1: Make students to form groups as per their comfort or make section Boys and Girls accordingly

Step 2: Mark in black board with two sections BOYS \& GIRLS or as per your comfort

Step 3: Instructions should be given to students prior to start of activity:

About activity:

Activity consists of three parts

a. Students should write keywords on black board 
alternatively by two groups.

b. Identifying simple and toughest keyword from list of keywords written on black board. [Important: Group A should identify Group B's Simple and toughest keyword and alternatively] and students should explain their relevance "why it's Simple and tough keyword" within the context.

c. Each individual group is instructed nominate one student from their group to perform next activity:

i. Nominated student from alternative group is instructed to write one simple grammar and one toughest grammar.

ii. Solutions to these problems should be given by alternative groups.

d. Students are instructed to link keywords based on the context to form loop such way that complete concept should be understood.

Step 4: Activity above mentioned is performed.

Step 4: Faculty keeps noting the points of batches

Step 5:Appreciation and prize distribution to winning batch and best performer in individual group.

1. Best performer will be selected by group members.

2. Prize distribution is made by technical staff of CSE Dept]

\section{B. JFLAPSimulation tool[4]:}

We present a hands-on approach to problem solving in the formal languages and automata theory course. Using the tool JFLAP, students can solve a wide range of problems that are tedious to solve using pencil and paper. In combination with the more traditional theory problems, students study a widerrange of problems on a topic. Thus, students explore the formal languages and automata concepts computationally and visually with JFLAP, and theoretically without JFLAP. In addition, we present a new feature in JFLAP, Turing machine building blocks. One can now build complex Turing machines by using other Turing machines as components or building blocks.

\section{About JFLAP:}

JFLAP is an instructional tool for creating and experimenting with several types of nondeterministic automata, grammars, regular expressions, L-systems, and experimenting with the conversion from one structure to another. With JFLAP one can build a finite automaton (FA), a pushdown automaton (PDA), or a multi-tape Turing machine (TM) and observe its simulation on several inputs. One can enter a regular grammar, a context-free grammar (CFG), or an unrestricted grammar and observe the brute force parsing of strings in this grammar with the result shown either as a derivation or a parse tree.

What our students done on this tool??

a. Students are given instructions about basic steps to use tool and instructed to explore more about tool by themselves.

b. Problems are given to students, solve using JFLAP tool.

How students solved:

a. Draw DFA, NFA and PDA using drag \& drop user interface provided by JFLAP tool.

b. Self assessment by providing strings as input.

We describe a hands-on approach to the FLA course that allows students to explore many of the FLA concepts computationally and visually using the tool JFLAP. We are not advocating to remove the proof type of exercises from the course, but rather to supplement them with hands-on explorations of related topics.

C. Activity based learning:

Activity based learning is a new technique played by students to explore in depth concepts to be understood by slow learners. State transitions are gestured by students; hence even slow learners could grasp the concepts.

D. Role play:

Each student on the 'tape' represented either $a$ or $b$ and stood in the following pattern

The given string is ...aabb...

- 'as' are represented by girls.

- 'bs' are represented by boys.

The Machine Head

- The 'machine head' student started in state A.

- StudentA with stick on his hand.

- When the machine head switched to state B, student hold two sticks on his hand.

- When machine $\mathrm{R} / \mathrm{W}$ head is switched to State $\mathrm{C}$ and move towards left till us gets a girl facing black board. Once we find a girl facing black board, $\mathrm{R} / \mathrm{W}$ head switches to A.

- In order to 'write' on the tape, when we see girl in a state A, she turns towards black board and the boy who act as $\mathrm{R} / \mathrm{W}$ will move towards right.

- When in state B if we see a boy then boy will turns towards black board.

- The boy who acts as R/W head will move towards left and be in sate $A$.

Now if we see a girl facing classroom then change 
state to $B$ and turn towards black board.

- Then in B if we see a boy then he will turns towards black board.

The process will continue till for every girl there is a boy. Then finally $\mathrm{R} / \mathrm{W}$ will be pointing to blank space where there are no students. Finally all girls and boys are facing towards black board.

E. Group Discussion:

a. AGroup consists of six students.

b. Each group is assigned a unique set of problems of different complexity.

c. Each group need to make a discussion and deliberations to come out with a solution

d. The faculty gave tips and hints while solving the problems.

\section{F. Crossword-}

A crossword is a word puzzle that normally takes the form of a square or a rectangular grid of white and black shaded squares. The goal is to fill the white squares with letters, forming words or phrases, by solving clues which lead to the answers. In languages that are written left-to-right, the answer words and phrases are placed in the grid from left to right and from top to bottom. The shaded squares are used to separate the words or phrases

What our students done on this tool??

a. Given information to students about crossword and creation of crossword.

b. Students were created Crossword for various terms related to Software architecture \& Modelling base.

c. Using the crossword enhance the critical thinking ability of students.

\section{G. Alice tool -}

3-D Interactive Graphics Programming Environment for Windows built by a Research Group at Carnegie Mellon University under the direction of Randy Pausch. Alice is built on top of the programming language Python. It is an innovative tool for teaching fundamental concepts of programming

What our students done on this tool??

a. Students are given instructions about basic steps to use tool and instructed to explore more about tool by themselves

b. Problems statements are given to students, write program using Alice tool.

c. Students understand the functioning of different programming language constructs with animation.

d. Students can visualize the working of the programming language constructs

\section{Result And Observations}

The main aim is to make active participation of students in the class room, efficient and lifelong learns.

Here we took two types of feed backs from students before and after completion of the activity:

1) Formal feedback.

2) Informal/subjective feedback.

$95 \%$ of the students say that the activity conducted in the classroom and tutorial helped them to understand the concepts clearly and gave them a platform, where they could do the discussion and solve the problems which helped them to enhance the critical thinking and the problem solving ability, because subjects are in mathematical and theoretical in nature.

Following questions are asked to the students at the end of the activity.

1. Your experience about activities conducted and how did you enjoyed?

2. Did activities helped to understand the concepts and rate it (out 5)-

- Yes -Rating

- No

3. Which activity you enjoyed more and helped better to understand the concept?
a. Ink and Think'
b. JFLAP tools
c. Activity based learning
d. Role play
e. Group discussion

4. Did you got complements for your active participation and what you got

5. You are Suggestions.

Results are analyzed based on the marks scored in Mid Semester Examination (MSE) and End Semester Examination (ESE). We compared End Semester Examination result with Mid Semester Examination result, students performance were better in End Semester Examination as show in fig.2.result analysis. As show in figure 2 more than 30 students have scored $70-80 \%$ marks in End Semester 
Examination as compare to mid semester examination. In Mid Semester Examination only 20 students scored marks in the range of $70-80 \%$.

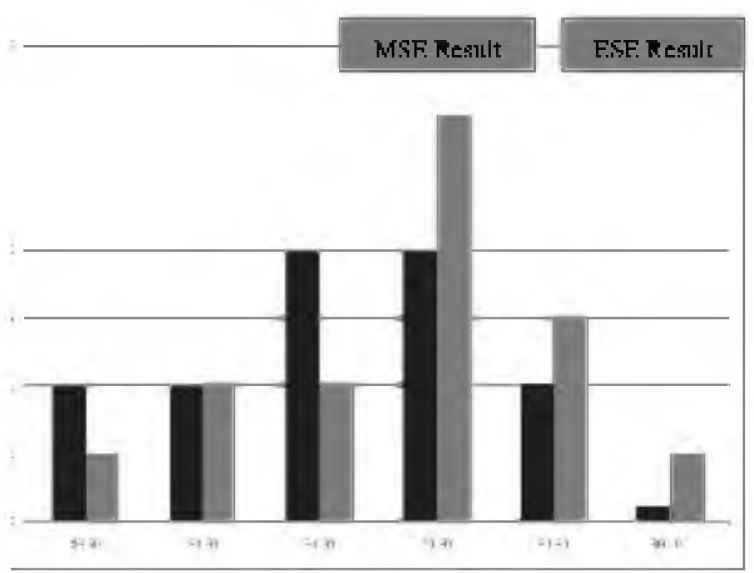

Figure 2. Result Analysis

The Table- 2 below shows survey conducted from the student's end of each activity, showing that students had enjoyed these activities in the class room and tutorial, thought these were good tools.

Table 2 : Survey conducted after each activity

\begin{tabular}{|c|c|}
\hline Questions & Response \\
\hline $\begin{array}{l}\text { How easy was it run the automata } \\
\text { you designed in JFLAP? } \\
\text { (80 respondents) }\end{array}$ & $\begin{array}{l}\text { Very Easy- } 30 \% \\
\text { Easy- } 65 \% \\
\text { Neither }-5 \% \\
\text { Difficult -5\% } \\
\text { Very Difficult -0\% } \\
\end{array}$ \\
\hline $\begin{array}{l}\text { The classroom activity based } \\
\text { learning has helped us understand the } \\
\text { concepts clearly. Where learning has } \\
\text { improved(( } 80 \text { respondents) } \\
\text { Group discussion method was useful } \\
\text { for students reinforcing difficult } \\
\text { concepts } \\
\text { What is the percentage of } \\
\text { Improvement? } \\
\text { ( } 80 \text { respondents) }\end{array}$ & $\begin{array}{l}\text { Strong agree -65\% } \\
\text { Agree-30\% } \\
\text { Neutral-3\% } \\
\text { Disagree-2\% } \\
\text { Strong agree -35\% } \\
\text { Agree-50\% } \\
\text { Neutral-14\% } \\
\text { Disagree-1\% }\end{array}$ \\
\hline $\begin{array}{l}\text { The Role play activity conducted in } \\
\text { the tutorial helped us to improve the } \\
\text { problem solving ability. } \\
\text { (80 respondents) }\end{array}$ & $\begin{array}{l}\text { Strong agree }-65 \% \\
\text { Agree-31\% } \\
\text { Neutral- } 4 \% \\
\text { Disagree- } 0 \% \\
\end{array}$ \\
\hline $\begin{array}{l}\text { Performing Think and Ink activity in } \\
\text { the classroom and tutorial made me } \\
\text { feel more engaged in the course and is } \\
\text { it assesses students quickly? } \\
\text { (80 respondents) }\end{array}$ & $\begin{array}{l}\text { Strong agree-70\% } \\
\text { Agree-28\% } \\
\text { Neutral-2\% } \\
\text { Disagree-0 }\end{array}$ \\
\hline $\begin{array}{l}\text { What is your overall } \\
\text { assessment of the } \\
\text { Crossword and Alice software? ( } 20 \\
\text { respondents) }\end{array}$ & $\begin{array}{l}\text { Very Poor- } 2 \% \\
\text { Poor }-4 \% \\
\text { Neither }-11 \% \\
\text { Good }-63 \% \\
\text { Very Good }-20 \%\end{array}$ \\
\hline
\end{tabular}

- $95 \%$ of the students said that JFLAP is a good tool to Design and understand the automata concept easily.

- $95 \%$ strongly agree that the activity conducted in the classroom helped them to understand the concepts easily.

- $85 \%$ of the students strongly agree that the Group discussion method was useful for reinforcing difficult concepts, where they could do the discussion and solve the problems which helped them to enhance the problem solving ability.

- $96 \%$ of the students strongly agree that the Role play activity conducted in the tutorial helped us to improve the critical thinking ability.

- $98 \%$ of the students strongly agree that Think and Ink activity conducted in the classroom helps them to understand the concepts easily and assesses quickly.

- $93 \%$ of the students said that Crossword and Alice software are good tools for self assessment and improvement.

\section{Conclusion}

Innovative methods of teaching were applied to courses viz. Theory of Computation and Software Architecture at II year B Tech \& I Year M Tech respective by the authors. Adopting the practical approach of teaching makes students to understand the concepts and relate to the real time applications easily. Activity and role based teaching learning was attempted in the classroom and tutorial sessions, which lead to the engage large classroom dynamic and active participation of the students. Group activities were attempted in tutorials which helped for reinforcing difficult concepts and allowed students to articulate their ideas, opportunity given to the groups present their answers and to explain the reasoning behind them. Crossword helped to stream line the concepts \& their relevance with features as a puzzle in horizontal/vertical/mix type. The Alice tool helped to model the object oriented world with different aspects \&modularization of thoughts as in real world statistics. The authors observed that this has resulted in increased participation and learning of students as evident in their performance. Students also felt that the pressure during examinations is reduced as they were comfortable with their learning through activities.

The use cases we performed to make joyful

10. An innovative and revolutionary approach of teaching programming concepts using Alice Infosys campus connects

11. http://en.wikipedia.org/wiki/Crossword. learning for students have given us great experience 
and those use case will be performed in other theoretical computer science subject.

\section{Reference}

[1] Mr.Shivananda R. Poojara, Mr.Khyamling A. Parane Department of CSE, RIT, Rajaramnagar "Technology Enhanced teaching Learning using palm devices" presented at IUCEE conference on ICTIEE 2013 BVB Hubli, published in springer 2014.

[2] Vijayalaskhmi M, Karibasappa K.G Dept. of CSE, BVB Hubli, "Activity Based Teaching Learning in Formal Languages and Automata Theory - An Experience" Journal of Engineering Education, 92 (2),7-25(2003).

[3] G. Subramonian and P. Prabha SRKV College of Education, Coimbatore, "A study on learning ability in elementary school mathematics based on ABL (Activity Based Learning) approach" International Journal for Life Sciences and Educational Research Vol.2 (1), pp. 8 -11, January-2014.

[4] Susan H. Rodger Dept. of CSE at Duke University," Increasing Engagement in Automata Theory with JFLAP" Visual Thinking Workshop
- Duke University May 4, 2009 Supported by NSF Grant DUE 0442513.

[5] Teo Chiang Juay Department of Mechanical Engineering, "using video clips, small group discussions and student surveys to teach a general education module (gem)" PDP-T Projects Jan/Feb 2013.

[6] Richard M. Felder Department of Chemical Engineering North Carolina State University "Designing and Teaching Courses to Satisfy the ABET Engineering Criteria" Journal of Engineering Education, 92 (1), 7-25 (2003).

[7] Bloom, Benjamin S. Taxonomy of Educational Objectives (1956). Published by Allyn and Bacon, Boston, MA. Copyright (c) 1984 by Pearson Education.

[8] Hopcroft. J. E., Motwani. R, and Ullman. J. D. "Introduction to Automata Theory, Language, and Computation". Addison-Wesley, 3rd edition, 2007

[9] Linz P, “An Introduction to Formal Languages and Automata", Narosa Puplishing, 4thedition, 2006.

[10]An innovative and revolutionary approach of teaching programming concepts using Alice Infosys campus connects

[11]http://en.wikipedia.org/wiki/Crossword. 